\title{
A Semi-Empirical Method to Calculate the Permeability of Homogeneously Fluidized Pyroclastic Material
}

\author{
Alain BURGISSER ${ }^{1,2,3}$ \\ burgisse@cnrs-orleans.fr \\ ${ }^{1}$ Univ. d'Orléans, ISTO, UMR 7327, 45071, Orléans, France \\ ${ }^{2}$ CNRS/INSU, ISTO, UMR 7327, 45071 Orléans, France \\ ${ }^{3}$ BRGM, ISTO, UMR 7327, 45071 Orléans, France
}




\begin{abstract}
This work postulates that highly polydisperse materials have an effective size distribution that controls permeability. Existence of such effective distribution implies that not all clasts participate to the permeable network resisting to gas flow and that clasts smaller than the minimal effective size are elutriated. When this concept is coupled to a generalized Blake-Kozeny equation, the resulting semi-empirical law links permeability to material properties only (bed void fraction, clast sizes and densities). After calibration of an experimental constant, it is able to replicate within $\pm 0.6 \log$ unit experimentally measured permeabilities of both loosely packed and expanded beds made of highly polydisperse (from $1 \mu \mathrm{m}$ to $4 \mathrm{~mm}$ ) pyroclastic deposits that were resampled so as to ensure homogeneous fluidization. The presence of an experimentally calibrated constant and the necessary absence of segregation during fluidization limit the extrapolation of the proposed law to any pyroclastic bed. Satisfactory fitting of the experimental values, however, confirms that the permeability of homogeneously fluidized beds is controlled by a balance between settling and elutriation. This balance suggests a first-order link between permeability and bed expansion, which has implications on the kinetics of dense pyroclastic flows.
\end{abstract}

Keywords: pyroclastic, permeability, polydisperse, fluidization. 


\section{Introduction}

Pyroclastic material is commonly highly polydisperse, with clasts ranging from a few meters down to a few microns or less. When traveling down the slopes of a volcano as dense pyroclastic density currents, such mixtures of clasts have a complex behavior that is partly inherited from the interactions with the hot interstitial volcanic gas and the entrained gas and partly due to their polydisperse nature. One approach of these complexities concentrates on the link between the microscopic, discrete nature of the clasts and the mesoscopic properties that arise when a subset of clasts within the main flow presents a coherent and representative dynamic behavior. Bed permeability, which characterizes the resistance encountered by the gas when it flows through a subset of clasts, is such a mesoscopic property. Permeability is a fertile concept because its quantification brought the idea that, like water-supported debris flows, pyroclastic flows may retain gas within the mixture, thus building excess gas pore pressure (Iverson and Vallance, 2001). Permeability enables one to calculate pore pressure diffusion, which in turn can quantify how long a bed remains in a fluidized state if no external gas is supplied (e.g., Roche et al., 2008; Roche, 2012). Under high pore pressure, pyroclasts are in a fluidized state because gas-grain interactions dominate over grain-grain interactions (e.g., Iverson, 1997; Iverson and Denlinger, 2001; Druitt et al., 2007). Importantly, the resulting low friction is a potential explanation of the long runout distance of pyroclastic flows (Iverson and Vallance, 2001; Girolami et al., 2008, Roche et al., 2008).

An accurate method to measure permeability of pyroclastic material is fluidization and bed settling (or collapse) experiments (see Wilson, 1984 and Druitt, 1995 for a full description of fluidization and settling behaviors). Fluidization and settling experiments are most often conducted by placing the sample material in rigs, which 
are generally hollow cylinders open at the top and capped at the base by a permeable plate through which gas is fed in order to maintain fluidization. Bed settling starts when the gas source is cut. Depending on the capacity of the bed to retain gas (i.e., bed permeability), complete settling can occur before all excess gas pore pressure vanishes. Such experiments clearly indicate that the degree of polydispersity influences permeability (Wilson, 1980; Wilson, 1984; Druitt, 1995; Gravina et al., 2004; Druitt et al., 2007). An additional complexity is that natural pyroclastic material efficiently segregates clasts, whether by size or density (Wilson, 1984). Mesoscopic properties such as porosity, clast size distribution, and permeability cease to be uniformly distributed within the fluidized bed as segregation proceeds (Di Felice, 1995). Fortunately, segregation can be avoided in experiments if samples are naturally well-sorted enough (Wilson, 1984) or pre-fluidized (Druitt et al. 2004; 2007; Girolami et al., 2008). The latter method involves a first fluidization of the natural bulk samples, which generates two segregated layers. Resampling of the homogeneous upper layer yields a pyroclastic material that can be fluidized without particle segregation. Such pre-fluidization allows samples to be homogeneously fluidized without bubbling or channelization from the loosely packed state up to 40 vol. $\%$ expansion (Druitt et al., 2007).

Another research avenue is the establishment of semi-empirical physical laws that link the dynamically measured permeability to other bed properties that can be measured independently. An important aspect of semi-empirical laws is that they shed partial light on the physics behind fluidization. The widely used Blake-Kozeny law of permeability (e.g., Bird et al., 2002) is such a relationship, albeit limited to monodisperse particle beds. It shows that the bed permeability to gas, $k_{c}$, is a function 
of particle size, $D_{c}$, and of the hydrodynamic porosity of the bed, $\alpha$ (i.e. the bed porosity without particle inner porosity):

$$
k_{c}=\frac{\alpha^{3} D_{c}^{2}}{A(1-\alpha)^{2}}
$$

The semi-empirical nature of Eq. (1) stems from the fact that the constant $A$ is experimentally determined and thus lumps together the combined effects of the tortuosity, interconnectedness, and irregular cross-sections of the gas pathways (MacDonald et al., 1991). The works of Carman (1937) and Wyllie and Rose (1950) have shown that $A$ is partly a function of the gas pathways tortuosity, which could then be introduced in Eq. (1) as an independent parameter. This is a good example on how further research on such laws leads to the identification and quantification of key physical characteristics of the permeable bed.

Most semi-empirical permeability laws for polydisperse beds ignore segregation and focus on homogeneously fluidized beds (e.g., McDonald et al. 1991; Hamilton, 1997; Gmachowski, 1998; Karacan and Halleck, 2003; Yu and Liu, 2004; Wu and Yu, 2007; Yin and Sundaresan, 2009; Cello et al., 2010). To date, however, these laws have not given satisfactory results when applied to natural pyroclastic material, mostly because of its highly polydisperse nature (Wilson, 1984; this work). Here, I build on the generalized Blake-Kozeny law of permeability proposed by McDonald et al. (1991) to propose a law suitable for highly polydisperse pyroclastic material. It is based on the hypothesis that the size distribution can be divided into one part that forms the permeable network and another that is being elutriated out of the bed by the gas flow. After calibration of an experimental constant, this law is used to link bed properties (bed void fraction, clast sizes and densities) to permeability measurements on homogeneously fluidized pyroclastic beds. Satisfactory fitting of the experimental 
values confirm the hypothesis that the permeable framework of highly polydisperse material is controlled by the balance between settling and elutriation. As a result, it is possible to propose a first-order equation linking bed permeability and bed expansion.

\section{Theoretical model of permeability}

The size distribution of pyroclastic material is commonly measured by sieving the material and weighing each class size, thus obtaining a size distribution per unit weight, $w\left(D_{j}\right)$, where $D_{j}$ is particle size and $j$ is the class indices that runs from the smallest class, 0 , to the coarsest class, $m$. Short forms $w(D)$ and $D$ will be used when all clasts sizes are concerned. Permeability is mostly sensitive to the surface area of each clasts size, which is best represented when distributions are expressed as number of clasts per unit weight, $n_{w}(D)$, or number of clasts per unit volume, $n(D)$.

Conversion between these various forms is carried out by assuming spherical clasts (e.g., Hamilton, 1997):

$$
n(D)=\rho_{B} n_{w}(D)=\frac{6 \rho_{B}}{\pi \rho_{p}(D) D^{3}} w(D)
$$

where $\rho_{B}$ is the bed bulk density and $\rho_{p}(D)$ is the density of clasts of size $D$. Bed bulk density can be related to the average particle density, $\rho_{\text {avg }}$, by $\rho_{B} \cong(1-\alpha) \rho_{\text {avg }}$, where $\rho_{\text {avg }}=\sum_{j} w\left(D_{j}\right) \rho_{p}\left(D_{j}\right)$

Bed collapse experiments start from a bed of particles contained in a fluidization rig and expanded by an upward flow of gas (Fig. 1A). The collapse is caused by the sudden stop of the gas source and the subsequent evacuation of gas from the expanded bed until all excess gas has left the bed. Owing to the setup geometry, bed motion can be considered as one-dimensional. If the bed is composed of a polydisperse material, 
its permeability, $k$, can be expressed as a generalized Blake-Kozeny equation (MacDonald et al., 1991):

$$
k=\frac{\alpha^{3}}{A(1-\alpha)^{2}}\left(\frac{M_{2}}{M_{1}}\right)^{2}
$$

where $M_{i}$ is the $i$-th moment of the particle size distribution as a function of particle number per unit volume (MacDonald et al., 1991):

$$
M_{i}=\int_{0}^{\infty} D^{i} n(D) d D
$$

Here, moments represent statistical characteristics of the size distribution by particle number: $M_{1}$ is the median and $M_{2}$ is the sorting of the distribution. Equation (3) has been shown to hold for ternary sand mixtures and permeabilities between $10^{-7}$ and $10^{-11} \mathrm{~m}^{2}$ (MacDonald et al., 1991). Typical pyroclastic material, however, contains clasts with size from meters down to micron. There is thus a need to extend the validity of Eq. (3) to highly polydisperse material.

Not all clasts participate to the network that hinders gas flow. It is easy to conceive that micron-sized clasts might be entrained by the upward gas flow through much larger particles, whereas large, isolated boulders act as outliers floating in a much finer matrix (Fig. 1A). Thus, there might be upper and lower bounds to the effective size distribution that controls how permeable the bed is. When pyroclastic size distributions are expressed as a function of particle numbers, the fines systematically dominate distributions (Fig. 1B-C, Kaminski and Jaupart, 1998), thereby strongly influencing the value of the moments. It thus would not be surprising if the permeabilities of pyroclastic material calculated using Eq. (3) are at least sensitive to the value of the lower bound of the effective distribution. Below I 
quantify such bounds in order to constrain the effective size distribution upon which moments should be calculated.

\section{The upper bound of the effective size distribution}

During collapse experiments, beds are contained in a fluidization rig. Isolated large clasts affect bed permeability by adding friction because of their surface area and by increasing the gas volume flux per unit area because they take a large fraction of the volume. Focusing on the former process, the upper bound of the effective size distribution controlling permeability can be thought as when there are so few large particles that the friction they cause to the escaping gas is comparable to that of the rig wall. To examine the contribution of these few particles to the overall permeability, I consider the permeability of the bed as if it contained only those coarse clasts of size $D_{c}$ at the concentration, $n\left(D_{c}\right)$, of the overall polydisperse distribution. In other words, the permeability, $k_{c}$, is that of a bed from which all particles have been removed but the ones of size $D_{c}$. The permeability of the resulting monodisperse bed can be described by Eq. (1), which can be written as (Bird et al., 2002, pp. 188-192):

$$
k_{c}=\frac{36 \alpha R_{h}^{2}}{A}
$$

where $R_{h}$ is the hydraulic radius (ratio of volume available for flow over the total wetted surface) given by (Bird et al., 2002):

$$
R_{h}=\frac{\alpha D_{c}}{6(1-\alpha)}
$$

This relationship has been shown to work with porosities up to 0.9 (Knackstedt and Zhang, 1994). At higher porosities, however, permeability becomes infinite as $\alpha$ becomes unity. This is because the hydraulic radius in Eq. (6) is only a function of the particles forming the bed. I thus modify Eq. (6) to incorporate wall effects while 
taking only into account the presence of particles of size $D_{c}$ among the whole size distribution.

Considering a cylindrical container of diameter $T$ and volume $V_{c}$, the volume available for flow is $\alpha V_{c}$ and the total wetted surface is the cumulated areas of all size $D_{c}$ clasts, $n\left(D_{c}\right) V_{c} \pi D_{c}{ }^{2}$, plus the area of the container walls, $4 V_{d} d T$. The hydraulic radius becomes:

$$
R_{h}=\frac{\alpha}{n\left(D_{c}\right) \pi D_{c}^{2}+4 / T}
$$

This formulation expresses the hydraulic radius of a monodisperse bed of particles of size $D_{c}$ and porosity $\alpha$ that is contained in a cylinder of diameter $T$. It is easy to verify that Eq. (7) equals Eq. (6) if the bed is monodisperse because then $n\left(D_{c}\right)(\pi / 6) D_{c}{ }^{3}=1-\alpha$ and wall effects are negligible $(T=\infty)$. If, on the other hand, no particles are present, $R_{h}=T / 4$ because then $\alpha=1$ and $n\left(D_{c}\right)=0$.

The denominator of Eq. (7) suggests that wall friction becomes as important as particle friction when $n\left(D_{c}\right) \pi D_{c}^{2}=4 / T$. Using this equality and transforming size distribution by particle number per unit volume, $n\left(D_{c}\right)$, into size distribution by weight fraction, $w\left(D_{c}\right)$, using Eq. (2) yields the minimum weight fraction of particles of a given size that affects the permeability of a polydisperse bed by friction:

$$
w\left(D_{c}\right)=\frac{2 \rho_{p}\left(D_{c}\right) D_{c}}{3 \rho_{B} T} \cong \frac{2 \rho_{p}\left(D_{c}\right) D_{c}}{3(1-\alpha) \rho_{\text {avg }} T}
$$

Owing to the linear dependence on particle size, one can expect this minimum amount of particles to be maximal at the coarse tail of the size distribution. This is consistent with $w\left(D_{c}\right)$ defining the upper bound of the effective size distribution. Equation (8) can thus be used to test whether the coarse tail of a pyroclastic size 
distribution can be truncated so as to ignore sizes that are present in quantities inferior to $w\left(D_{c}\right)$.

\section{The lower bound of the effective size distribution}

Permeability is generally measured by injecting gas through the bed at a rate just below bed fluidization and expansion. The pressure gradient created by the upward gas flow is thus exactly balancing that of the bed at maximum loose packing. Under such conditions and neglecting the gas contribution to bed weight, the gas pressure gradient is a simple function of the particle average density, $\rho_{a v g}$, and the bed porosity at maximum packing. The velocity, $U_{E}$, at which gas escapes from the bed (a.k.a. gas volume flux per unit area, or interstitial gas velocity) can thus be found by applying Darcy's law:

$U_{E}=\frac{k(1-\alpha) \rho_{\text {avg }} g}{\mu \alpha}$

where $\mu$ is gas viscosity and $g$ is the gravity acceleration.

A very small particle of size $D_{e}$ trapped in a coarse bed will be elutriated if the gas velocity is greater than its terminal fall velocity $U_{T}$ (Fig. 1A). Wilson and Huang (1979) studied the terminal fall velocity of volcanic ash particles in air and proposed a relationship valid over a wide range of particle sizes and shapes. Assuming laminar gas flow around the particles, their relationship can be simplified to:

$U_{T}=\frac{\rho_{e} D_{e}^{2} g F^{0.828}}{18 \mu}$

where $\rho_{e}$ is particle density, $D_{e}$ is particle size, and $F$ is a measure of the nonsphericity of the clasts. The factor $F$ is equal to $\left(x_{2}+x_{3}\right) / 2 x_{1}$, where $x_{1}, x_{2}$, and $x_{3}$ are the longest, middle, and shortest axes of the clast, respectively. The simplification induces 
an error $\leq 1 \%$ on $U_{T}$ for clasts $\leq 125 \mu \mathrm{m}$, which will be shown to be accurate enough for permeability calculations.

In order to find the lower bound of the effective size distribution, I postulate that there is a particle size, $D_{e}$, of density $\rho_{p}\left(D_{e}\right)=\rho_{e}$ below which elutriation takes place while coarser particles form the network of the permeable bed. This occurs when $U_{E}=U_{T}$, which simplifies to:

$\frac{\rho_{e} D_{e}^{2} F^{0.828}}{18}=\frac{\rho_{\text {avg }} k(1-\alpha)}{\alpha}$

Expressing the permeability with Eq. (1) and rearranging gives:

$D_{e} \frac{M_{1}}{M_{2}}=\sqrt{\frac{18 \rho_{\text {avg }}}{A F^{0.828} \rho_{e}}} \frac{\alpha}{\sqrt{1-\alpha}}$

The $M_{i}$ are the moments of the effective particle size distribution from the coarser end to the size just above $D_{e}$. Two ways to solve Eq. (12) are presented below.

The most direct but somewhat cumbersome method is to calculate the moments directly from the sieved size distribution. Traditionally, sieve data are acquired by weighing sample fraction every $\phi$ unit, where particle size is equal to $2^{-\phi} \mathrm{mm}(0 \phi=1$ $\mathrm{mm},-1 \phi=2 \mathrm{~mm}$, etc.). The class size is thus halving at each $\phi$ increment. The distribution $n(D)$ from which moments are calculated, however, is defined in number of particle by linear class size in meters. So, once weight fractions are converted to numbers of particles, the moments have to be calculated incrementally by, for example, a middle Riemann sum:

$M_{i}=B \sum_{j=e+1}^{m} D_{j}^{i+1} n\left(D_{j}\right)$

where $e+1$ is the class size just above $D_{e}$, and $B$ is a constant equal to $\left(2^{1 / p}-2^{-1 / p}\right) / 2$ with $p$ being the sieve interval. The constant $B$ is thus $3 / 4$ if the sieve interval is $1 \phi$ 
$(p=1)$ and $1 / \sqrt{8}$ if the interval is $1 / 2 \phi(p=2)$. The elutriation size $D_{e}$ is obtained by finding numerically the root of Eq. (12). The bed permeability at a given porosity can then be calculated using $M_{1}, M_{2}$, and Eq. (3). To simplify calculations, the number of particle per unit weight in Eq. (2) can also be used, as bed bulk density cancels out when calculating the ratio $M_{2} / M_{1}$.

Formally, perfect match between both sides of Eq. (12) is not possible because the moments expressed by Eq. (13) are discrete values whereas the value of $D_{e}$ is only limited by machine precision. In other words, $D_{e}$ is considered as a continuous value in Eq. (12) and is allowed to take values between bin increments, whereas $n\left(D_{e+1}\right)$ will be rounded to the nearest bin in Eq. (13). A workaround is to refine the values of $n(D)$ to a smaller interval by setting $p=10$ and perform a linear interpolation of $n\left(D_{j}\right)$ between the actual sieved intervals. This is the solution proposed in the Electronic Supplementary Material under the form of an MS Excel spreadsheet.

Another way to solve Eq. (12) is to fit a continuous expression of the form $n(D)=\delta D^{-\beta}$ to the size distribution, where $\delta$ is a fitting constant and $\beta$ is the fractal dimension of the distribution (e.g., Kaminski and Jaupart, 1998). If $\beta \neq 2$ and $\beta \neq 3$, moments of the continuous distribution can readily be integrated using Eq. (4) from the smallest size of the effective distribution, $D_{e+1}$, which is the size above $D_{e}$, to the coarsest size, $D_{m}$. Maintaining the order of terms in both sides of the equation, Eq. (12) becomes:

$D_{e}\left(\frac{3-\beta}{2-\beta}\right) \frac{D_{m}^{2-\beta}-D_{e+1}^{2-\beta}}{D_{m}^{3-\beta}-D_{e+1}^{3-\beta}}=\sqrt{\frac{18 \rho_{\text {avg }}}{A F^{0.828} \rho_{e}}} \frac{\alpha}{\sqrt{1-\alpha}}$

Equation (14) has to be solved numerically, but a special case of interest can be solved for analytically. It requires that $\beta=2.5, \rho_{a v g}=\rho_{e}$, and $D_{e+1}=D_{e}$ : 
$D_{e}=\frac{18 \alpha^{2} D_{m}}{A F^{0.828}(1-\alpha)}$

Permeability can then easily be calculated using Eqs. (3) and (15):

$k=\frac{18 \alpha^{5} D_{m}^{2}}{A^{2} F^{0.828}(1-\alpha)^{3}}$

\section{Experimental permeability data from the literature}

Druitt et al. (2007) have measured the permeability of pyroclastic beds at various stages of expansion above maximum packing and at different temperatures. The beds were formed of natural pyroclastic material sieved as to eliminate the coarser part, either from $4 \mathrm{~mm}(-2 \phi)$ up, or from $250 \mu \mathrm{m}(2 \phi)$ up, respectively. The resulting grain sizes were analyzed down to $1 \mu \mathrm{m}(10 \phi)$. Beds were formed of $2.5 \mathrm{~kg}$ of material enclosed in a 14-cm-wide fluidization rig fed by nitrogen between 50 and $500{ }^{\circ} \mathrm{C}$. They measured the bulk density of the loosely packed bed, from which I recalculated bed porosity (Table 1). Expanded bed experiments were treated the same way as maximum packing ones, except that bed porosity is that of the expanded bed. Permeabilities of loosely packed beds reported in Table 1 were taken from their Fig. 9, and the largest source of error is the measure of fluidization velocities. Errors linked to permeabilities of loosely packed beds are thus considered to be of the same magnitude as the errors on fluidization velocities ( $\pm 0.08 \log$ unit, or $\sim 20 \%$ ). Permeabilities of expanded beds reported in Table 1 were calculated using their equation 10 with the exponent $n=4$ (Table 1). Errors linked to expanded beds were quantified by taking the two extreme values for the exponent $n$ ( 2 and 6 for $<2 \phi$ samples, and 7 and 12 for <-2 $\phi$ samples, Druitt et al., 2007).

The shape factor, $F$, of individual clasts is not reported by Druitt et al. (2007), but a range of likely values can be calculated from Wilson and Huang (1979) data. The 26 
smallest ash particles from their Table 1 yield a median $F$ value of 0.4 with a minimum of 0.27 and a maximum of 0.57 . These ash particles have median axes $\leq 3 \phi$, which will be shown a posteriori to be an appropriate size for the lower bound of the effective size distribution, $D_{e}$. Such a departure from spherical shape $(F=1)$ is due to the fact that fine clasts are generally broken bubble walls, glass shards, and crystals of angular shape. Since the proportions of these types of elements vary between bin sizes and between deposits, the full range of $F$ values will be considered.

\section{Results}

The semi-empirical nature of the method proposed herein stems from the fact that the experimental constant $A$ need to be determined before solving for permeability. The constant $A$ partly characterizes the irregularity of the clasts belonging to the effective distribution and partly depends on the particle spatial organization (Knackstedt and Zhang, 1994). Many values have been suggested for this constant, ranging from the theoretical value of 44.4 for spheres to experimentally fitted values of 150 or 180 (MacDonald et al., 1991) and to even larger values for fractal media (Xu and Yu, 2008). I use the data of Druitt et al. (2007) to constrain the likely range of $A$ by considering that bed permeability is known (Table 1). Calculation of $A$ can be carried out by fixing $F$, solving Eq. (11) for $D_{e}$, calculating the moments using Eq. (13), and solving for $A$ using Eq. (3).

Figure 2 shows values of $A$ given by the 38 permeabilities reported in Table 1 for three representative values of $F$ (minimum, median, and maximum). Values of $A$ display positively skewed normal distributions lying between 130 and 526, a span that includes but extends to much larger values than the commonly assumed 150 for monodisperse beds (e.g., Roche, 2012). The factor $F$ is a weak control of $A$, and the range of values within one standard deviation is restricted between 203 and 289 with a 
median value of 242. This suggests that a single value of $A$ might represent bed permeability to an acceptable degree of accuracy.

Using the same data of Druitt et al. (2007), I applied the generalized BlakeKozeny equation (1) on the effective size distribution with single values for $F$ and $A$ ( 0.4 and 242, respectively) and compared the theoretical result to their measured permeabilities (Fig. 3). Uncertainties on calculated permeabilities were obtained by combining the minimum, median, and maximum values of $F$ and $A$, respectively. The best results were obtained by calculating the moments from the sieved size distribution that were interpolated to a finer $(0.1 \phi$ or $p=10)$ interval and without constraining the upper bound of the size distribution (see the implemented resolution in Supplementary Material). As a result, the lower bound of the effective distribution satisfies Eq. (12) using the discrete class sizes from sieve data in Eq. (13). Theoretical values lay less than $\pm 0.6 \log$ unit (a factor of 3.8 ) from their experimental counterparts, offering a good match over 3 orders of magnitude. The concept of effective size distribution coupled with fixed values for $F$ and $A$ thus adequately links bed characteristics and permeability. A similar conclusion is reached if the permeabilities of Table 1 are randomly split into a subset from which an $A$ value is obtained, and another subset against which predicted values are compared to. This suggests that the 38 measures of Table 1 constitute a sufficient sample size to determine $A$.

The lower bound of the effective distribution of the loosely packed beds lay between 5 and $7 \phi$ (Fig. 4). Once expanded, the lower bound shifts towards coarser clasts to lie between 3 and $6 \phi$. These values justify a posteriori the ash sizes used to constrain $F$. Data of Fig. 4 suggest that clasts $<7 \phi(<8 \mu \mathrm{m})$ were being elutriated during the steady-state stage of all the fluidization experiments. Druitt et al. (2004) 
report that ash $<100 \mu \mathrm{m}$ was being elutriated from sample NES250 when gas supply was at or above maximum pressure velocity ( $U_{m p}$, Wilson, 1984). This is consistent with $D_{e}$ values up to $40 \mu \mathrm{m}$ for that sample (Table 1). More precise evaluations of elutriation sizes from experimental data would be a test of the robustness of the concept of effective size distribution.

Samples used by Druitt et al. (2007) were sieved at $1 \phi$ intervals, and best results were obtained when refining these intervals to $0.1 \phi$. Figure $5 \mathrm{~A}$ shows the effect of not interpolating these distributions to a finer interval. Discrepancies of more than an order of magnitude arise for expanded beds. Permeabilities of packed beds, however, are not sensitive to interval refinements.

The most straightforward method to solve for the moments is to fit a power law to the size distribution because it leads to the analytical solution of Eq. (16). Several assumptions, however, must be made to apply Eq. (16). The first assumption is that all clasts have the same, average density. Calculations of Fig. 4 used the density distribution measured by Druitt et al. (2007). When assuming that $\rho_{p}(D)=\rho_{\text {avg }}$, calculated permeabilities are increased by less than $0.08 \log$ unit (16\%) for fine beds and less than $0.25 \log$ unit (43\%) for coarse beds, regardless of bed expansion. These errors are less than those induced by the uncertainties on $F$ and $A$, which suggests that this assumption $\left(\rho_{\text {avg }}=\rho_{e}\right)$ is valid.

Examination of Table 1 suggests that the additional assumptions required to use the continuous method in Eq. (16) to obtain the moments of the distribution seem reasonable $\left(\beta=2.5\right.$ and $\left.D_{e+1}=D_{e}\right)$. Agreement between theoretical and experimental values, however, holds only for the finer beds (with clasts $<250 \mu \mathrm{m}$; Fig. 5B). It seems unlikely that the major discrepancy observed for coarser beds is caused by fixing to 2.5 the value for the exponent of the fitted distribution, as coarser beds have 
$\beta$ values closest to 2.5 (Table 1). This was confirmed by taking the best-fit $\beta$ value for each sample and solving Eq. (14) numerically, which yielded a similar divergence for the coarser beds. Instead, this deviation seems to be caused by the fact that power-law distributions do not accurately represent the moments of the coarser distributions, despite excellent fits with sieve data $\left(\mathrm{R}^{2}\right.$ values are between 0.96 and 0.99, Fig. 1B). Figure 6 shows that there could be significant differences between moments calculated from the discrete distribution and the ones calculated from best-fit power laws. It depends on both the goodness-of-fit of the distribution and the relevant value for $D_{e}$.

\section{Constraining bounds of the effective size distribution}

Clasts less abundant than $w\left(D_{c}\right)$ are predicted to have a negligible effect on permeability. Thus, the first and second moment of the size distribution shall not be sensitive to small amounts of coarse clasts in order for Eq. (3) to correctly predict permeability. This can be tested by comparing a distribution that includes a small amount of coarse clasts to a distribution that does not. First, take the distribution of the fine sample NES250 with a 52 vol.\% bed porosity (Table 1), the coarsest clasts of which are $<2 \phi(250 \mu \mathrm{m})$ and calculate $w\left(D_{c}\right)$ for $-1 \phi(2 \mathrm{~mm})$ clasts using Eq. (8) (Fig. 7). Then, add small amounts of $-1 \phi$ clasts while keeping the bed porosity constant and calculate the resulting permeability using Eqs. (3), (12), and (13). Figure 7 compares the theoretical value $w\left(D_{c}\right)$ with the evolution of permeability as coarse ($1 \phi)$ clasts are added. It illustrates nicely that coarse clasts can safely be neglected if less abundant than $w\left(D_{c}\right)$ because the coarser they are, the less influence they have on bed permeability. This is in agreement with experiments on horizontally flowing fluidized beds, which demonstrated that small quantities of coarse particles added to a fluidized monodisperse bed do not influence its flowing characteristics (Roche et al., 
2005). Calculating $w\left(D_{c}\right)$ for all the samples in Table 1 shows that the coarsest clasts of the sieve data always participate to the permeable network.

The lower bound of the effective distribution, however, has values much larger than the smallest clasts present in the samples (Fig. 4). The bed permeability with unconstrained lower bound can be calculated by assuming that particles given as $<10$ $\phi(1 \mu \mathrm{m})$ in Druitt et al. (2007) were $11 \phi(0.5 \mu \mathrm{m})$. For sample NES250, forcing the lower bound, $D_{e}$, to $11 \phi$ yields $4.18 \times 10^{-13} \mathrm{~m}^{2}$. This is an order of magnitude below the measured value $\left(3.63 \times 10^{-12}\right.$; Table 1$)$, which illustrates nicely that the original law of MacDonald et al. (1991) needs to be modified so as to take into account that clasts below a certain size do not influence bed permeability.

\section{Discussion}

The present model replicates permeabilities of both loosely packed and expanded beds and links permeability to material properties only (bed void fraction, clast sizes and densities). These results have several implications on the physics of fluidization. First, the interactions between clasts and gas control the system, which is trying to maintain equilibrium between settling and elutriating particles. As expected, particleparticle interactions play a subordinate role, as the effective distribution is only a function of the average relative speed between gas and particles and of the settling speed of non-interacting particles. This remains true as long as gas pore pressure exists within the settling bed, regardless whether touching clasts form chains or exchange momentum through collisions or frictional contact.

Fitting power laws to size distributions of pyroclastic material is common practice (e.g., Kaminski and Jaupart, 1998; Horwell et al., 2001; Maria and Carey, 2007), and many permeability determination methods based on power-law size distribution have 
been proposed (e.g., Gmachowski, 1998; Karacan and Halleck, 2003; Wu and Yu, 2007). Figure 8 compares the experimental permeabilities reported in Table 1 and those calculated with the methods proposed by Gmachowski (1998) and Karacan and Halleck (2003). Such comparison suggests that the permeability of pyroclastic material cannot easily be related to power-law-fitted distributions. A shortcoming of the Karacan and Halleck (2003) method is that it assumes that pore size distributions follow power-laws that are linked to those of clast size distributions. While this might be true for loosely packed beds, it is not the case for expanded beds because expansion only affects porosity. Difficulties encountered when applying the method by Gmachowski (1998) are caused by the coarse tail of the distributions, which not only deviate from power laws, but also is present in amounts greater than $w\left(D_{c}\right)$, thereby affecting bed permeability. Power-law size distribution is thus an approximate description of the fractal nature of pyroclastic beds that has a limited use to quantify bed permeability.

\section{Implications for experimental work}

The semi-empirical law developed herein depends on several critical assumptions that condition its applicability to experiments on fluidized material. Experiments of Druitt et al. (2007) were conducted on static beds having reached steady-state fluidization. In the light of the law developed herein, it means that the balance between fluidization and elutriation of fines was reached. At the inception of fluidization, however, unsteady fluidization prevails (see Di Felice, 1995, for a full description) and the fines are trapped within the highly concentrated bed. Their elutriation speed is thus different from that predicted by the terminal velocity of a single particle in Eq. (10) because of the small size of the interstices and the presence 
of other finer particles. This effect is expected to increases when the proportion of fines increases.

The need to experimentally calibrate the constant $A$ limits the extrapolation of the proposed law to any pyroclastic bed. Hamilton (1997) suggested replacing $A$ by a first principle expression depending on bed porosity, thus proposing a universal law. The $A$ values so calculated span from 162 to 216 for the samples in Table 1. This is below the best-fit value of 242 and, when used in Eqs. (3) and (12), these $A$ values result in poor fitting of the permeabilities with discrepancies reaching up to $3 \log$ units. As Hamilton (1997) assumes that particles are spheres, which is not the case of the pyroclasts studied herein, the poor fit suggests that $A$ is partly controlled by the degree of irregularity of the clasts.

The relationship between bed expansion and permeability is a complex one to establish because expansion is linked to porosity, which is difficult to quantify in polydisperse material (Wilson, 1984; Roche et al., 2005; Druitt et al., 2007). Expanded bed permeabilities reported in Table 1 were calculated thanks to a relationship based on the work of Richardson and Zaki (1954). It states that permeability is roughly proportional to the ratio of expanded to loosely packed porosity elevated to a power ranging from 2 to 12 (Druitt et al., 2007). Following the same reasoning, a first-order assessment of how expansion controls permeability can be done based on the continuous method in Eq. (16) because it captures the relative evolution of permeability with porosity. The ratio between the permeability, $k_{0}$, of a loosely packed bed of porosity, $\alpha_{0}$, and the permeability, $k_{1}$, of an expanded bed of porosity, $\alpha_{0}(1+E)$, where $E$ is the fraction of expansion, is given by:

$$
\frac{k_{1}}{k_{0}}=\frac{\left(1-\alpha_{0}\right)^{3}(1+E)^{5}}{\left[1-\alpha_{0}(1+E)\right]^{3}}
$$


If the Blake-Kozeny relationship (1) is taken instead of Eq. (16), this ratio becomes:

$$
\frac{k_{1}}{k_{0}}=\frac{\left(1-\alpha_{0}\right)^{2}(1+E)^{3}}{\left[1-\alpha_{0}(1+E)\right]^{2}}
$$

Figure 9A plots bed permeability as a function of bed expansion. It shows that Eq. (17) captures the increase of permeability upon expansion within an order of magnitude for four out of the five samples of Table 1, whereas Eq. (18) does not. The large misfit of sample NES4000 is caused by the strong departure from the assumption $\rho_{e}=\rho_{\text {avg }}$ for large $E$ values. Expansion thus exerts a much stronger control on permeability than the Blake-Kozeny relationship suggests. This is partly due to the fact that the porosity function $\alpha^{3} /(1-\alpha)^{2}$ in Eq. (1) is only valid for packs of uniformly sized spheres, and partly due to the fact that Eq. (18) incorrectly assumes that particle size is constant, regardless of expansion.

The permeability law tested in Fig. 2 is applied to statically fluidized beds, although pyroclasts are flowing along the slopes of the volcano. Observations suggest that sedimentation in static beds occurs as a sharp front aggrading the deposits because gas pore pressure keeps the settling part of the collapsing bed at its initial porosity (Druitt et al., 2007). To first order, the permeability of the initially expanded bed can thus be linked to sedimentation rate, although such link is made complex by non-linear variations of pore pressure during settling (Montserrat et al., 2012). Girolami et al. (2008) have shown that the same pyroclastic material as used by Druitt et al. (2007) settles at the same speed when flowing along a horizontal base than when it is contained in a static rig. Following these authors and integrating the present results suggest that the sedimentation rate in homogeneously fluidized, polydisperse flows is also controlled by a simple balance between elutriation of smaller particles 
and gas retention by coarser particles. A first order, permeability-based sedimentation law derived from the present work would be quite versatile, as it can be incorporated into depth-averaged flow model (e.g., Kelfoun, 2009) through the concept of pore pressure diffusion (Montserrat et al., 2012; Roche, 2012), and used in multiphase models (e.g., Dufek and Bergantz, 2007) because permeability characterizes the drag between the solid phase and the carrier gas.

\section{Implications for natural pyroclastic flows}

One of the strengths of the semi-empirical law presented herein is that it does not depend on gas viscosity and is valid at magmatic temperatures since Druitt et al. (2007) data were acquired between 50 and $550^{\circ} \mathrm{C}$. Some of the insights developed above can thus be extended to flowing pyroclastic density currents. Two issues, however, limit the scope of these insights.

The first issue is whether the permeability determination described herein can be applied to natural, coarser material. The strongest limitation is that natural materials are generally more poorly sorted than those of Table 1 and will segregate upon fluidization (Wilson, 1984). This restricts the extension of the law proposed herein to materials that fluidize in a homogeneous fashion. With this limit is mind, Eq. (8) can be used to assess whether the coarser end of the size distribution affects permeability. Since the concept of rig size used herein loses pertinence when addressing unconfined systems, a ratio between deposit thickness and boulder size might be more appropriate to characterize outliers. Two additional aspects can cause trouble when applying the law to natural materials. First, although $F$ was not determined on the same pyroclasts as the ones used in Druitt et al. (2007), assuming a value of 0.4 gives satisfactory results over three orders of magnitude (Fig. 3). This might no longer hold for coarser beds, which suggests that further testing of the current conclusion that shape 
irregularities of the elutriated clasts have a small influence on bed permeability is needed. Testing can easily be conducted by measuring $F$ on the same clasts as those composing the fluidized beds. Second, most published sieve data of pyroclastic material do not feature the average clast density of each sieve interval. Results of this study indicate that using a constant, average clast density for the whole distribution underestimates bed permeability. This effect increases with the abundance of coarse particles but remains below the overall uncertainty level of the method for beds with clasts up to $4 \mathrm{~mm}$. Most natural material being, however, much coarser than a few $\mathrm{mm}$, extrapolation of the present model to natural material most likely necessitates clast density distributions.

The second issue is whether particle-particle interactions, negligible at the flow speeds reached in the laboratory $(1.5 \mathrm{~m} / \mathrm{s})$ for $<4 \mathrm{~mm}$ clasts mixtures, are also negligible in the case of much faster pyroclastic flows. Several recent lines of evidence suggest that fluidization plays a key role in the transport system of natural flows. Research centered on dense granular mechanics that ignores the role of the gas (e.g., Forterre and Pouliquen, 2008) has proposed rheology laws that explain nonfluidized, laboratory flows much more accurately (e.g., Lube et al., 2007) than natural flows (Kelfoun et al., 2009; Doyle et al., 2010). Quantifications carried out with pore pressure diffusion values corresponding to permeabilities from $10^{-13}$ to $10^{-9} \mathrm{~m}^{2}$ indicate that large-scale flows are likely to remain fluidized over much of their travel time (Roche et al., 2010; Roche, 2012). Even if this is encouraging, it remains that the delicate balance expressed by equating gas speed to settling speed in Eq. (11) will be upset by incomplete fluidization (i.e., loss of pore pressure, Roche et al., 2008), attrition, or irruption of momentum-driven boulders in the settling bed. Assuming nevertheless that the kinetics of fluidized pyroclastic flows is controlled by such a 
balance, one can try estimating the consequences of upsetting it by a modification of the flow expansion. Events affecting flow porosity include, for instance, thickening following a break in the pathway slope. The approximate relationship between of bed expansion and permeability (Fig. 9B) suggests that a $~ 30 \%$ change in bed expansion results in one order of magnitude change in permeability. This suggests that the kinetics of pore pressure diffusion in natural flows is only moderately sensitive to flow thickness changes, and that flows might be able to quickly re-establish their balanced permeability after being subjected to perturbations such as slope changes.

\section{Conclusions}

This work postulates that highly polydisperse materials have an effective size distribution that controls permeability. Existence of such effective distribution implies that not all clasts participate to the permeable network resisting to gas flow and that clasts smaller than the minimal effective size are elutriated. When this concept is coupled to a generalized Blake-Kozeny equation, the resulting law is able to predict the permeabilities of pyroclastic material within $\pm 0.6 \log$ unit. The dataset used to carry out the comparison is based on natural pyroclastic deposits that were resampled so as to ensure homogeneous fluidization (Druitt et al., 2007). Results suggest that the effective size distribution is not sensitive to small amounts of large particles, which are correctly treated as outliers floating in a finer matrix. If Eq. (8) is verified, there is no need to constrain the upper bound of the effective size distribution other than by sieve data. The lower bound is best constrained by solving Eq. (12) using the method in Eq. (13) and interpolating sieve data to $0.1 \phi$ intervals. Bed permeability can then be obtained using Eq. (3) (see Supplementary Material). The presence of an experimentally calibrated constant and the necessary absence of segregation during fluidization limit the extrapolation of the proposed law to any given pyroclastic bed. 
The result that permeability is controlled by a balance between settling of the coarse clasts and elutriation of the fines has nevertheless implications on the kinetics of dense pyroclastic flows. This balance implies a first-order relationship between permeability and expansion, which suggests that pore pressure diffusion in homogeneously fluidized parts of natural pyroclastic flows is only moderately sensitive to perturbations of the flow thickness.

\section{Acknowledgements}

I would like to thank T. Druitt, O. Roche, and J.-L. Bourdier for stimulating discussions and C. Wilson and an anonymous reviewer for beneficial reviews. This work was partially supported by the European Research Council grant 202844 under the European Framework Program 7.

\section{References}

Bird, R.B., Stewart, W.E., Lightfoot, E.N., 2002. Transport phenomena. Wiley, New York.

Carman, P.C., 1937. Fluid flow through granular beds. Trans. Inst. Chem. Eng. London, 15: 150-166.

Cello, F., Di Renzo, A., Di Maio, F.P., 2010. A semi-empirical model for the drag force and fluid-particle interaction in polydisperse suspensions. Chem. Eng. Sci. 65, 3128-3139.

Di Felice, R., 1995. Hydrodynamics of liquid fluidization. Chem. Eng. Sci. 50, 1213-1245.

Doyle, E.E., Hogg, A.J., Mader, H.M., Sparks, R.S.J., 2010. A two-layer model for the evolution and propagation of dense and dilute regions of pyroclastic currents. J. Volcanol. Geotherm. Res. 190, 365-378.

Druitt, T., 1995. Settling behaviour of concentrated dispersions and some volcanological applications. J. Volcanol. Geotherm. Res. 65, 27-39.

Druitt, T.H., Bruni, G., Lettieri, P., Yates, J.G., 2004. The fluidization behaviour of ignimbrite at high temperature and with mechanical agitation. Geophys. Res. Lett. 31, L02604, doi:10.1029/2003GL018593.

Druitt, T.H., Avard, G., Bruni, G., Lettieri, P., Maez, F., 2007. Gas retention in fine-grained pyroclastic flow materials at high temperatures. Bull. Volcanol. 69, 881-901.

Dufek, J., Bergantz, G.W., 2007. Suspended load and bed-load transport of particle-laden gravity currents: The role of particle-bed interaction. Theoret. Comput. Fluid Dyn., doi 10.1007/s00162-007-0041-6. 
Foreterre, Y., Pouliquen, O., 2008. Flows of dense granular media. Annu. Rev. Fluid Mech. 40, 1-24.

Girolami, L., Druitt, T.H., Roche, O., Khrabrykh, Z., 2008. Propagation and hindered settling of laboratory ash flows. J. Geophys. Res. 113, B02202, doi:10.1029/2007JB005074.

Gmachowski, L., 1998. Flow drag in polydisperse systems. Water Res. 32, 2655-2659.

Gravina, T., Lirer, L., Marzocchella, A., Petrosino, P., Salatino, P., 2004. Fluidization and attrition of pyroclastic granular solids. J. Volcanol. Geotherm. Res. 138, 27-42.

Hamilton, R.T., 1997. Darcy constant for multisized spheres with no arbitrary constant. AIChE J. 43, 835-836.

Horwell, C.J., Brana, L.P., Sparks, R.S.J., Murphy, M.D., Hards, V.L., 2001. A geochemical investigation of fragmentation and physical fractionation in pyroclastic flows from the Soufrière Hills volcano, Montserrat. J. Volcanol. Geotherm. Res. 109, 247-262.

Iverson, R.M., 1997. The physics of debris flows. Rev. Geophys. 35, 245-296.

Iverson, R.M., Denlinger, R.P., 2001. Flow of variably fluidized granular masses across threedimensional terrain 1. Coulomb mixture theory. J. Geophys. Res. 106, 537-552.

Iverson, R.M., Vallance, J.W., 2001. New views of granular mass flows. Geology 29, 115118.

Kaminski, E., Jaupart, C., 1998. The size distribution of pyroclasts and the fragmentation sequence in explosive volcanic eruptions. J. Geophys. Res. 103, 29759-29779.

Karacan, C.Ö., Halleck, P.M., 2003. A fractal model for predicting permeability around perforation tunnels using size distribution of fragmented grains. J. Petrol. Sci. Eng. 40, 159-176.

Kelfoun, K., Samaniego, P., Palacios, P., Barba, D., 2009. Testing the suitability of frictional behaviour for pyroclastic flow simulation by comparison with a well-constrained eruption at Tungurahua volcano (Ecuador). Bull. Volcanol. 71, 1057-1075.

Knackstedt, M.A., Zhang, X., 1994. Direct evaluation of length scales and structural parameters associated with flow in porous media. Phys. Rev. E 50, 2134-2138.

Lube, G., Huppert, H.E., Sparks, R.S.J., Freundt, A., 2007. Static and flowing regions in granular collapses down channels. Phys. Fluids 19, 043301, doi:10.1063/1.2712431.

MacDonald, M.J., Chu, C.-F., Guilloit, P.P., Ng, K.M., 1991. A generalized Blake-Kozeny equation for multisized spherical particles. AIChE J. 37, 1583-1588.

Maria, A., Carey, S., 2007. Quantitative discrimination of magma fragmentation and pyroclastic transport processes using the fractal spectrum technique. J. Volcanol. Geotherm. Res. 161, 234-246.

Montserrat, S., Tamburrino, A., Roche, O., Niño, Y., 2012. Pore fluid pressure diffusion in defluidizing granular columns. J. Geophys. Res. 117, F02034, doi:10.1029/2011JF002164.

Richardson, J.F., Zaki, W.N., 1954. Sedimentation and fluidisation. Part 1. Trans. Inst. Chem. Eng. 32, 35-53.

Roche, O., 2012. Depositional processes and gas pore pressure in pyroclastic flows: an experimental perspective. Bull. Volcanol. in press, doi:10.1007/s00445-012-0639-4.

Roche, O., Gilbertson, M.A., Phillips, J.C., Sparks, R.S.J., 2005. Inviscid behaviour of finesrich pyroclastic flows inferred from experiments on gas-particle mixtures. Earth Planet. Sci. Lett. 240, 401-414. 
Roche, O., Montserrat, S., Niño, Y., Tamburrino, A., 2008. Experimental observations of water-like behavior of initially fluidized, dam break granular flows and their relevance for the propagation of ash-rich pyroclastic flows. J. Geophys. Res. 113, B12203, doi:10.1029/2008JB005664.

Roche, O., Montserrat, S., Niño, Y., Tamburrino, A., 2010. Pore fluid pressure and internal kinematics of gravitational laboratory air-particle flows: Insights into the emplacement dynamics of pyroclastic flows. J. Geophys. Res. 115, B09206, doi:10.1029/2009JB007133.

Wilson, C.J.N., 1980. The role of fluidization in the emplacement of pyroclastic flows: an experimental approach. J. Volcanol. Geotherm. Res. 8, 231-249.

Wilson, C.J.N., 1984. The role of fluidization in the emplacement of pyroclastic flows, 2: experimental results and their interpretation. J. Volcanol. Geotherm. Res. 20, 55-84.

Wilson, L., Huang, T.C., 1979. The influence of shape on the atmospheric settling velocity of volcanic ash particles. Earth Planet. Sci. Lett. 44, 311-324.

$\mathrm{Wu}$, J., Yu, B., 2007. A fractal resistance model for flow through porous media. Int. J. Heat Mass Transfer 50, 3925-3932.

Wyllie, M.R.J, Rose, W.D., 1950. Application of the Kozeny Equation to consolidated porous media. Nature 165, 972, doi:10.1038/165972a0.

Xu, P., Yu, B., 2008. Developing a new form of permeability and Kozeny-Carman constant for homogeneous porous media by means of fractal geometry. Advances Water Resources 31, 74-81.

Yin, X., Sundaresan, S., 2009. Fluid-particle drag in low-Reynolds-number polydisperse gassolid suspensions. AIChE J. 55, 1352-1368, doi:10.1002/aic.11800.

Yu, B., Liu, W., 2004. Fractal analysis of permeabilities for porous media. AIChE J. 50, 4657. 
Table 1: Size distribution parameters from pyroclastic beds and permeability determinations.

\begin{tabular}{|c|c|c|c|c|c|c|c|c|}
\hline Sample & $\beta$ & $\rho_{\text {avg }} / \rho_{e}{ }^{*}$ & $\begin{array}{c}\text { Porosity } \\
\%\end{array}$ & $\begin{array}{c}\text { Expansion }^{*} \\
\%\end{array}$ & $\begin{array}{l}k \text { measured* } \\
\mathrm{m}^{2}\end{array}$ & $\begin{array}{c}k \text { discrete } \\
\mathrm{m}^{2}\end{array}$ & $\begin{array}{c}k \text { continuous } \\
\mathrm{m}^{2}\end{array}$ & $\begin{array}{c}D_{e} \\
\phi\end{array}$ \\
\hline \multirow{8}{*}{ NES250 } & \multirow{8}{*}{2.39} & 0.995 & 52 & 0 & $3.6310^{-12}$ & $4.1910^{-12}$ & $3.5210^{-12}$ & 6.4 \\
\hline & & 0.995 & 52 & 0 & $5.6010^{-12}$ & $4.1310^{-12}$ & $3.4410^{-12}$ & 6.4 \\
\hline & & 0.995 & 53 & 0 & $6.7910^{-12}$ & $4.6410^{-12}$ & $4.1410^{-12}$ & 6.3 \\
\hline & & 0.995 & 54 & 0 & $1.6410^{-11}$ & $5.8610^{-12}$ & $4.6210^{-12}$ & 6.2 \\
\hline & & 0.995 & 63 & 21 & $1.0510^{-11}$ & $4.0210^{-11}$ & $2.0610^{-11}$ & 5.1 \\
\hline & & 0.995 & 63 & 21 & $1.5810^{-11}$ & $3.6610^{-11}$ & $1.9710^{-11}$ & 5.1 \\
\hline & & 0.995 & 66 & 24 & $2.3710^{-11}$ & $6.0010^{-11}$ & $3.0710^{-11}$ & 4.9 \\
\hline & & 0.995 & 68 & 26 & $6.7610^{-11}$ & $8.7010^{-11}$ & $4.2110^{-11}$ & 4.6 \\
\hline \multirow{8}{*}{ DOR250 } & \multirow{8}{*}{2.18} & 0.981 & 46 & 0 & $3.3010^{-12}$ & $5.1010^{-12}$ & $1.3310^{-12}$ & 6.1 \\
\hline & & 0.981 & 47 & 0 & $4.7510^{-12}$ & $5.8010^{-12}$ & $1.5210^{-12}$ & 6.0 \\
\hline & & 0.981 & 47 & 0 & $6.2610^{-12}$ & $6.2310^{-12}$ & $1.7010^{-12}$ & 6.0 \\
\hline & & 0.981 & 49 & 0 & $1.3710^{-11}$ & $7.7610^{-12}$ & $2.2410^{-12}$ & 5.8 \\
\hline & & 0.981 & 58 & 26 & $9.1010^{-12}$ & $2.6510^{-11}$ & $9.1710^{-12}$ & 5.2 \\
\hline & & 0.981 & 61 & 31 & $1.7310^{-11}$ & $4.4010^{-11}$ & $1.5810^{-11}$ & 5.0 \\
\hline & & 0.981 & 63 & 33 & $2.5410^{-11}$ & $5.4410^{-11}$ & $2.0010^{-11}$ & 4.8 \\
\hline & & 0.981 & 65 & 32 & $5.9710^{-11}$ & $7.4810^{-11}$ & $2.6910^{-11}$ & 4.7 \\
\hline \multirow{8}{*}{ PDD250 } & \multirow{8}{*}{2.23} & 0.989 & 52 & 0 & $9.1010^{-12}$ & $6.1610^{-12}$ & $3.2910^{-12}$ & 6.1 \\
\hline & & 0.989 & 52 & 0 & $1.1310^{-11}$ & $6.4510^{-12}$ & $3.5410^{-12}$ & 6.1 \\
\hline & & 0.989 & 58 & 0 & $1.6210^{-11}$ & $1.5610^{-11}$ & $9.6110^{-12}$ & 5.6 \\
\hline & & 0.989 & 60 & 0 & $2.7210^{-11}$ & $2.1410^{-11}$ & $1.2510^{-11}$ & 5.4 \\
\hline & & 0.989 & 56 & 9 & $1.3810^{-11}$ & $1.2710^{-11}$ & $7.0110^{-12}$ & 5.7 \\
\hline & & 0.989 & 59 & 13 & $2.1310^{-11}$ & $1.9310^{-11}$ & $1.0710^{-11}$ & 5.5 \\
\hline & & 0.989 & 69 & 19 & $5.6410^{-11}$ & $1.2610^{-10}$ & $5.8610^{-11}$ & 4.4 \\
\hline & & 1.041 & 72 & 20 & $1.1510^{-10}$ & $2.5710^{-10}$ & $9.2110^{-11}$ & 4.0 \\
\hline \multirow{6}{*}{ NES4000 } & \multirow{6}{*}{2.79} & 0.942 & 42 & 0 & $3.7610^{-12}$ & $2.0710^{-12}$ & $1.8010^{-10}$ & 6.6 \\
\hline & & 0.942 & 41 & 0 & $4.7510^{-12}$ & $2.0910^{-12}$ & $1.5910^{-10}$ & 6.6 \\
\hline & & 0.942 & 43 & 0 & $6.7310^{-12}$ & $3.0010^{-12}$ & $2.1210^{-10}$ & 6.4 \\
\hline & & 0.961 & 58 & 38 & $9.4010^{-11}$ & $1.4110^{-10}$ & $2.3510^{-9}$ & 4.0 \\
\hline & & 0.961 & 60 & 46 & $2.3310^{-10}$ & $2.3410^{-10}$ & $3.3410^{-9}$ & 3.7 \\
\hline & & 1.132 & 62 & 45 & $4.3010^{-10}$ & $9.5510^{-10}$ & $4.7110^{-9}$ & 2.7 \\
\hline \multirow{8}{*}{ DOR4000 } & \multirow{8}{*}{2.59} & 0.879 & 39 & 0 & $6.4010^{-12}$ & $6.9110^{-12}$ & $1.0310^{-10}$ & 5.7 \\
\hline & & 0.879 & 38 & 0 & $5.4110^{-12}$ & $6.3310^{-12}$ & $8.9810^{-11}$ & 5.7 \\
\hline & & 0.879 & 39 & 0 & $1.1510^{-11}$ & $7.5110^{-12}$ & $1.0810^{-10}$ & 5.7 \\
\hline & & 0.879 & 40 & 0 & $1.2810^{-11}$ & $8.5910^{-12}$ & $1.2110^{-10}$ & 5.6 \\
\hline & & 0.879 & 49 & 26 & $4.0610^{-11}$ & $3.7810^{-11}$ & $5.8310^{-10}$ & 4.8 \\
\hline & & 0.879 & 49 & 28 & $3.6310^{-11}$ & $3.1710^{-11}$ & $5.4810^{-10}$ & 4.9 \\
\hline & & 0.879 & 51 & 29 & $9.2510^{-11}$ & $4.6810^{-11}$ & $7.2710^{-10}$ & 4.7 \\
\hline & & 0.879 & 52 & 31 & $1.2310^{-10}$ & $5.8510^{-11}$ & $9.1110^{-10}$ & 4.6 \\
\hline
\end{tabular}

*Values from Druitt et al. (2007). See text for details. 


\section{Figure Caption}

Figure 1: A. Schematic representation of a settling polydisperse bed. Clasts can be divided in three categories with respect to settling dynamics, which define the effective part of the size distribution that controls bed permeability. Small clasts (black) have settling velocities smaller than gas flow $\left(U_{T}<U_{E}\right)$ and are elutriated. Outsized clasts have sizes, $D_{m}$, comparable to that of the settling rig, $T$, and do not influence bed permeability. Intermediate clasts having settling velocities larger than gas flow $\left(U_{T}>U_{E}\right)$ form the permeable framework. On the right are two representations of sieve data from the five fluidized pyroclastic samples analyzed by Druitt et al. (2007). B. Normalized number of clasts per size bin. C. Normalized weight percent per size bin. Permeability is most sensitive to the shape of the distribution in $\mathbf{B}$.

Figure 2: Spread of values for the permeability coefficient $A$ as a function of three values of the clast shape factor $F$. Population size is 38 (see Table 1).

Figure 3: Measured vs. calculated permeabilities, $k$, of pyroclastic beds. Fine beds contain clasts $<2 \phi$ and coarse beds contain clasts $<-2 \phi$. Calculated permeabilities are termed discrete because sieve data are directly used to determine permeability. Size distribution binning is every $0.1 \phi$, a resampling from the original data. Vertical error bars on calculated permeabilities were obtained by combining the minimum, median, and maximum values of $F$ and $A(0.27 ; 0.4 ; 0.57$ and $203 ; 242 ; 289$, respectively). Errors inferior to symbol size are not shown. Measured permeabilities are from data in Druitt et al. (2007): expanded beds permeabilities were obtained from data regression, generating the vertical error bars, and packed beds permeabilities were 
obtained from direct measurements, generating errors inferior to symbol size (see text).

Figure 4: Lower bound of the effective size distribution, $D_{e}$, as a function of bed expansion. Fine beds contain clasts $<2 \phi$ and coarse beds contain clasts $<-2 \phi$.

Figure 5: Measured vs. calculated permeabilities, $k$, of pyroclastic beds. Fine beds contain clasts $<2 \phi$ and coarse beds contain clasts $<-2 \phi$. Grey areas represent the data field of Fig. 3. A. Discrete calculation, in which sieve data are directly used to determine permeability. Size distribution binning is every $1 \phi$, as in original data. B. Continuous calculation, in which best-fits of sieve data (Table 1) are used to determine permeability.

Figure 6: Difference between moments calculated from the discrete data of the sieve analysis using Eq. (13) and the ones calculated from best-fit power laws using Eq. (14). Fine bed is sample NES250 and coarse bed is sample NES4000. Both $M_{2} / M_{1}$, which can be viewed as an effective clast size, and the lower bound of the effective distribution, $D_{e}$, are shown in $\phi$ units.

Figure 7: Permeability of bed formed by NES250 clasts as a function of added weight fraction of coarser clasts of size $-1 \phi(2 \mathrm{~mm})$. Also shown is the theoretical weight fraction, $w\left(D_{c}\right)$, below which added clasts have a small effect on permeability of a bed contained in a 14-cm-diameter fluidization rig. The effective size distribution (bounded at $D_{e}$ ) with $1 \phi$ interval has been used.

Figure 8: Measured vs. calculated permeabilities, $k$, of pyroclastic beds using two methods (open symbols: Gmachowski, 1998; closed symbols: Karacan and Halleck, 2003) assuming power-law size distributions. In the first method, sieve intervals of $0.1 \phi$ were used with their corresponding $\beta$ values ( $D$ in equations 13 and 15 of Gmachowski, 1998). In the second method, sieve 
intervals of $0.1 \phi$ were used to calculate the total grain surface area while assuming no tortuosity of the gas pathways, a complete fragmentation, and a pore fractal dimension of two (respectively $D_{T}=1, \phi_{f}=$ bed porosity, and $D_{P}$ $=2$ in Karacan and Halleck, 2003). Triangles are fine beds and circles are coarse beds. Grey squares are permeabilities of Fig. 3 .

Figure 9: Effects of expansion on bed permeability. A. Calculated bed permeabilities as a function of expansion (Table 1). Only the coarsest samples NES4000 and DOR4000 are shown for clarity; the two finer samples (NES250 and DOR250) having respective curves similar to those of DOR4000.

Continuous lines are calculated using the discrete size distributions with 0.1 $\phi$ intervals and changing the value of $\alpha$. Dashed lines are calculated using Eq. (17) and dotted lines are calculated using Eq. (18). B. Increase in permeability as a function of bed expansion for three loosely packed porosities. The increase is calculated using Eq. (17) and expressed as the ratio of expanded bed permeability $\left(k_{1}\right)$ over loosely packed bed permeability $\left(k_{0}\right)$. 

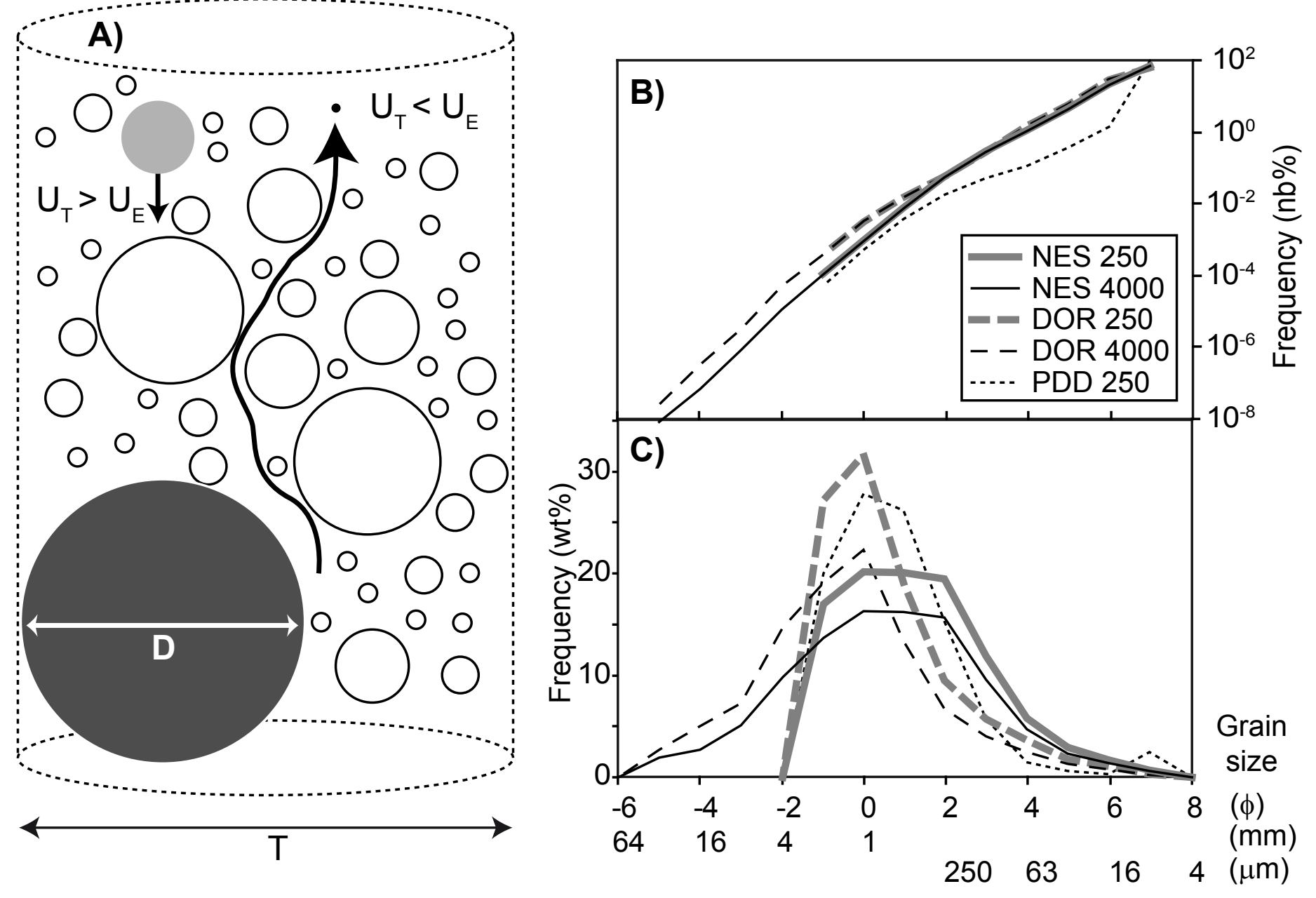

FIGURE 1 


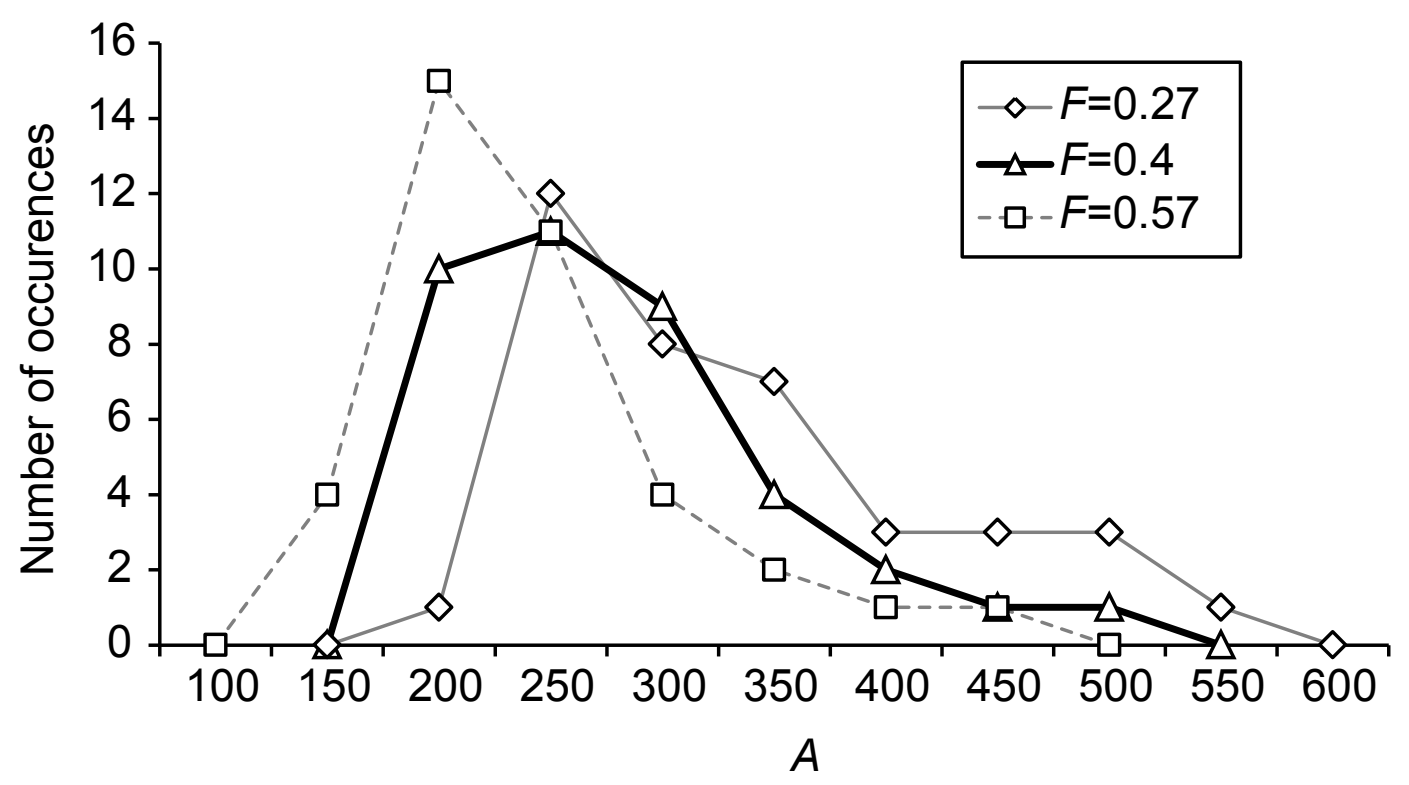

FIGURE 2 




FIGURE 3 


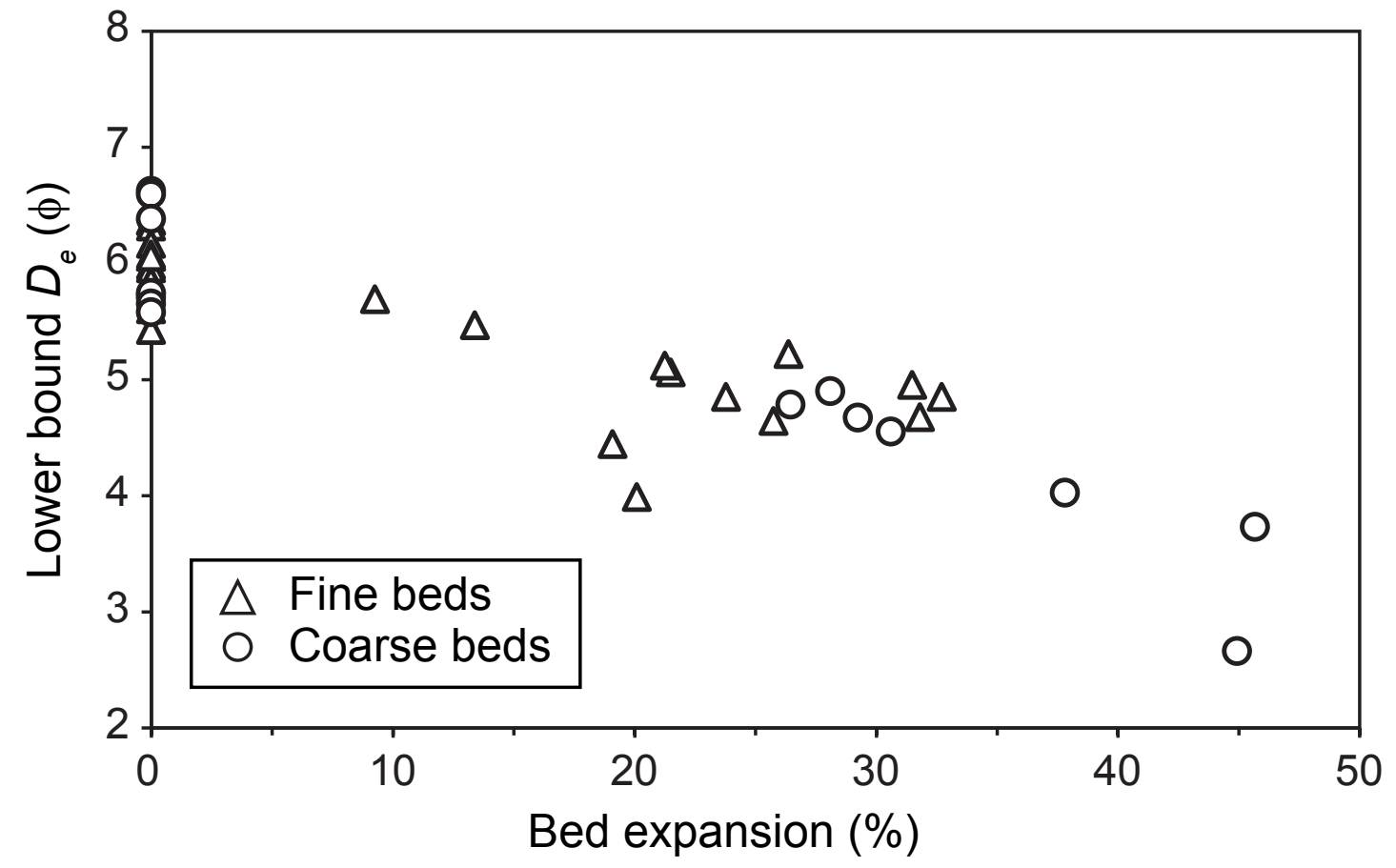

FIGURE 4 

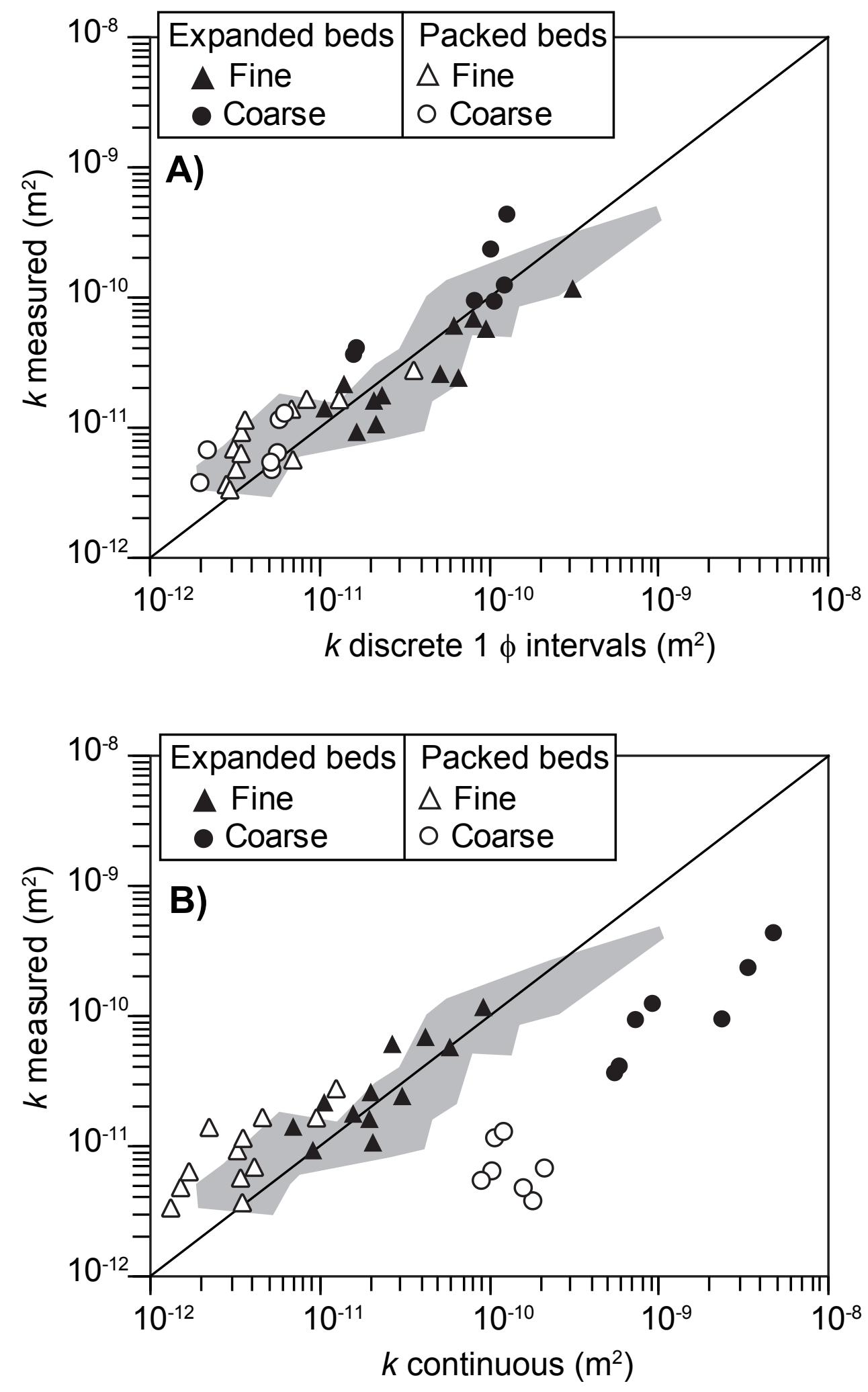

FIGURE 5 


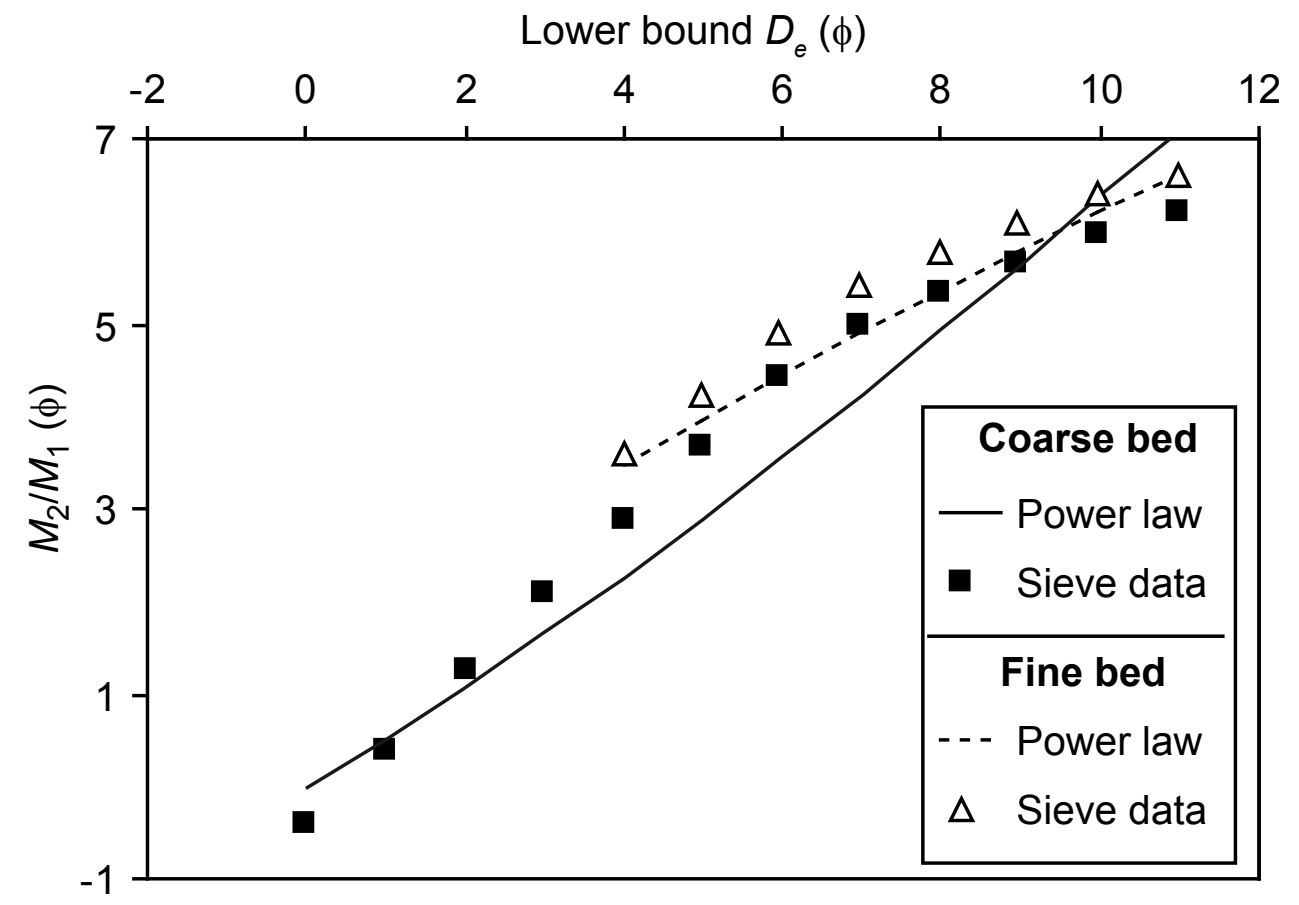

FIGURE 6 


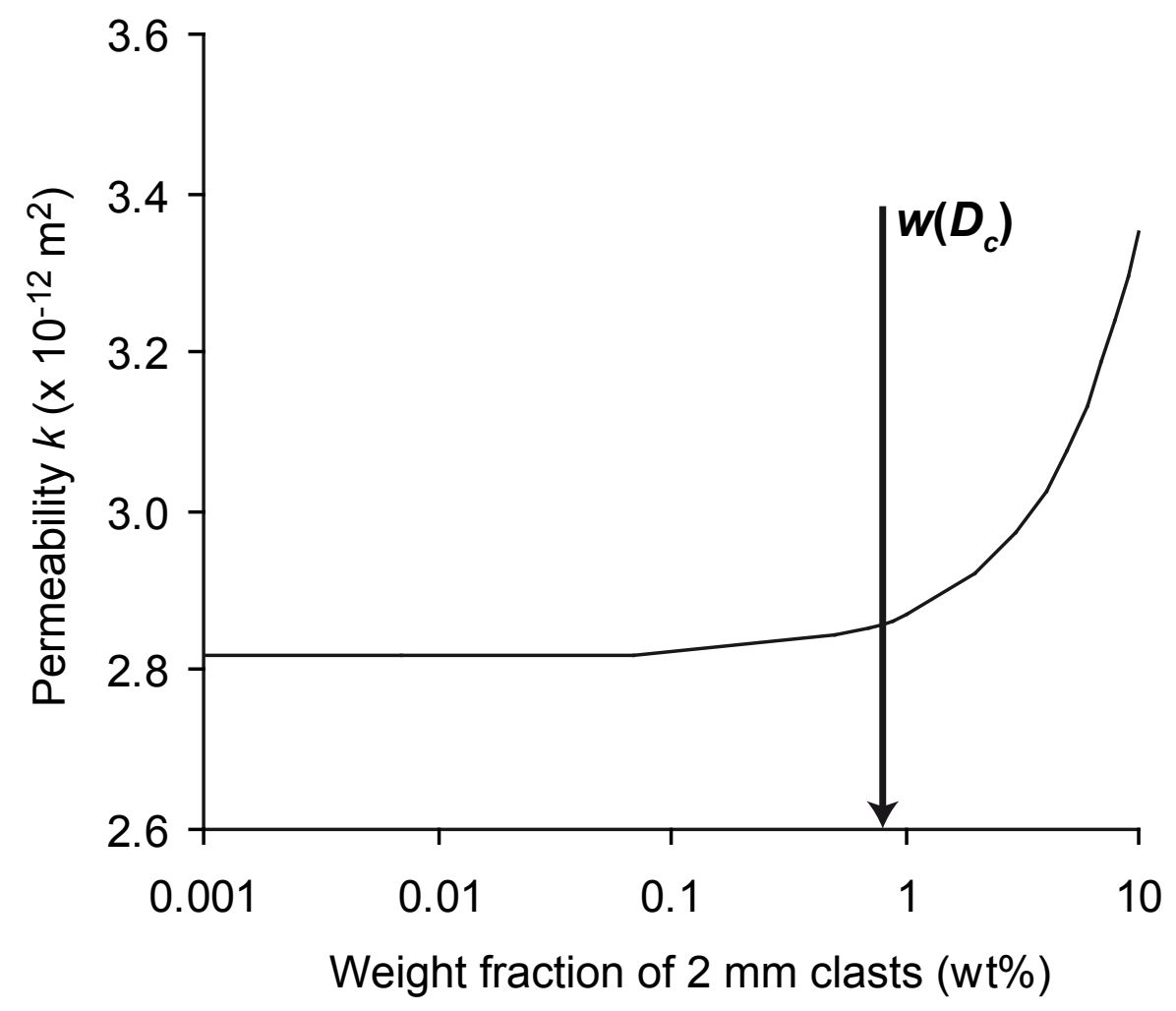

FIGURE 7 


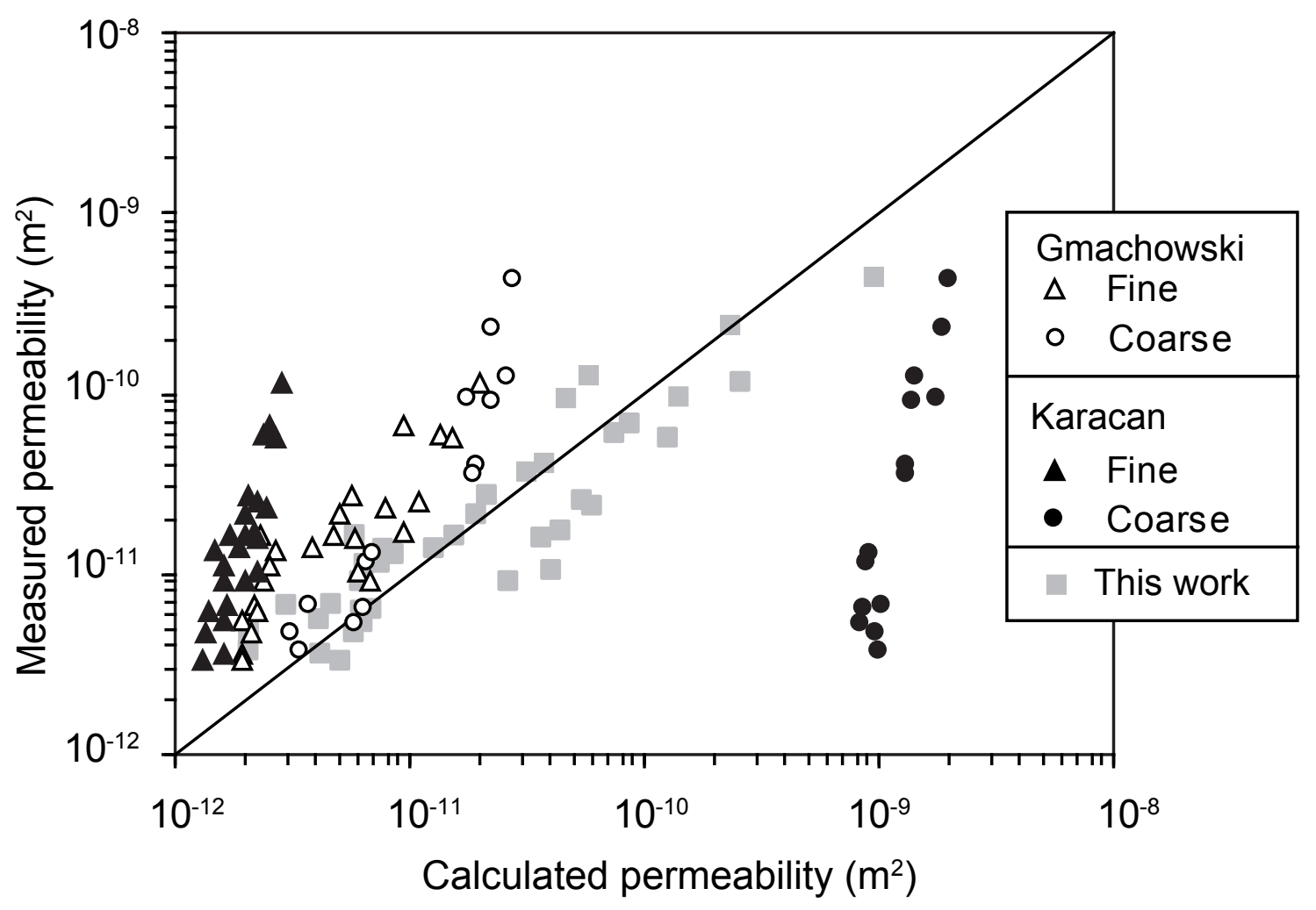

FIGURE 8 

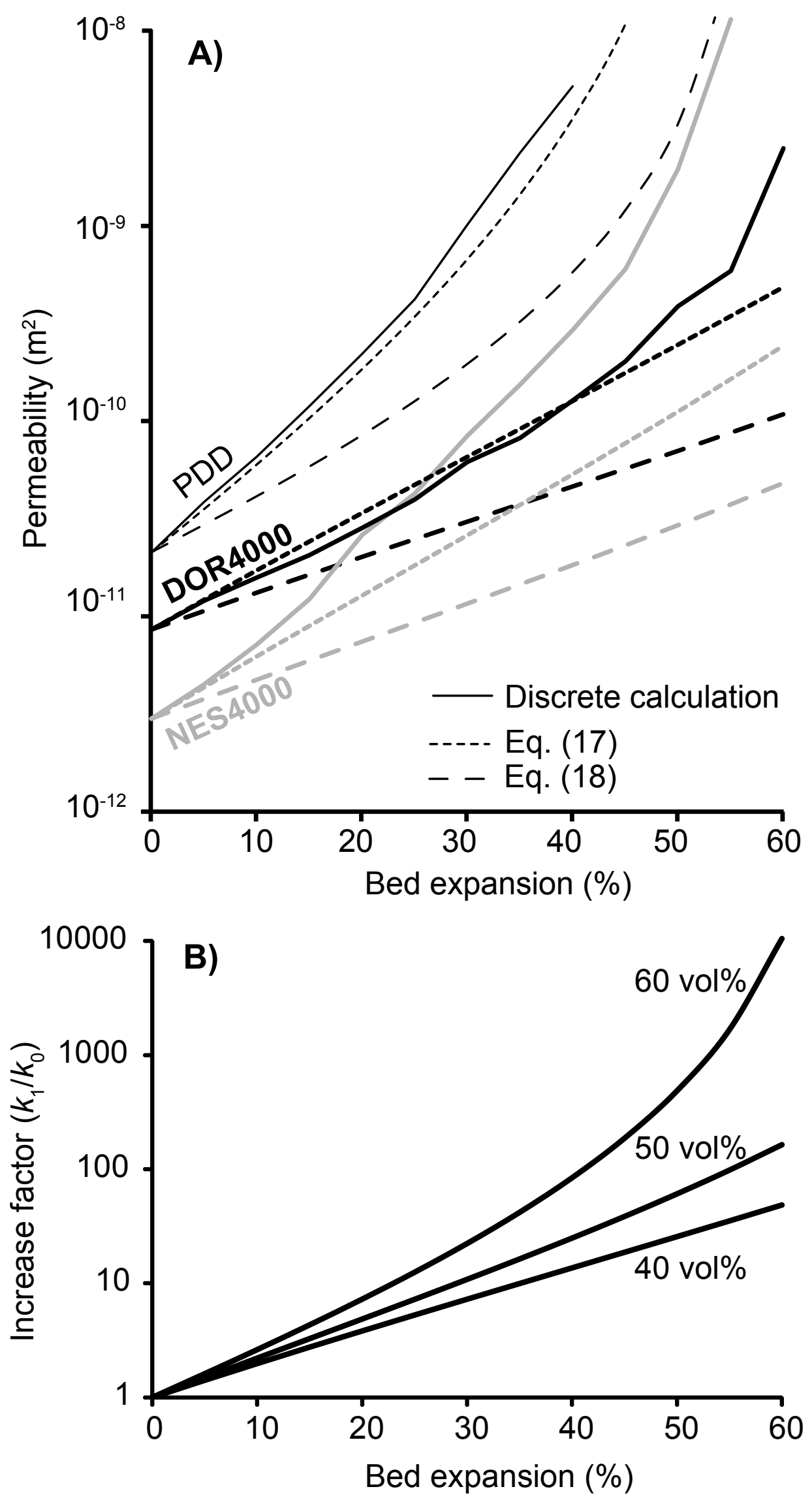

FIGURE 9 